\title{
c-KIT receptor expression is strictly associated with the biological behaviour of thyroid nodules
}

\author{
Sara Tomei ${ }^{1 \dagger}$, Chiara Mazzanti ${ }^{{ }^{*}+}$, Ivo Marchetti ${ }^{2}$, Leonardo Rossi ${ }^{3}$, Katia Zavaglia', Francesca Lessi ${ }^{1}$, \\ Alessandro Apollo ${ }^{1}$, Paolo Aretini ${ }^{1}$, Giancarlo Di Coscio ${ }^{2}$ and Generoso Bevilacqua ${ }^{1}$
}

\begin{abstract}
Background: A large amount of information has been collected on the molecular tumorigenesis of thyroid cancer. A low expression of c-KIT gene has been reported during the transformation of normal thyroid epithelium to papillary carcinoma suggesting a possible role of the gene in the differentiation of thyroid tissue rather than in the proliferation. The initial presentation of thyroid carcinoma is through a nodule and the best way nowadays to evaluate it is by fine-needle aspiration (FNA). However many thyroid FNAs are not definitively benign or malignant, yielding an indeterminate or suspicious diagnosis which ranges from 10 to $25 \%$ of FNAs. BRAF mutational analysis is commonly used to assess the malignancy of thyroid nodules but unfortunately it still leaves indeterminate diagnoses. The development of molecular initial diagnostic tests for evaluating a thyroid nodule is needed in order to define optimal surgical approach for patients with uncertain diagnosis pre- and intra-operatively.
\end{abstract}

Methods: In this study we extracted RNA from 82 FNA smears, 46 malignant and 36 benign at the histology, in order to evaluate by quantitative Real Time PCR the expression levels of c-KIT gene.

Results: We have found a highly preferential decrease rather than increase in transcript of c-KIT in malignant thyroid lesions compared to the benign ones. To explore the diagnostic utility of c-KIT expression in thyroid nodules, its expression values were divided in four arbitrarily defined classes, with class I characterized by the complete silencing of the gene. Class I and IV represented the two most informative groups, with $100 \%$ of the samples found malignant or benign respectively. The molecular analysis was proven by ROC (receiver operating characteristic) analysis to be highly specific and sensitive improving the cytological diagnostic accuracy of 15\%.

Conclusion: We propose the use of BRAF test (after uncertain cytological diagnosis) to assess the malignancy of thyroid nodules at first, then the use of the c-KIT expression to ultimately assess the diagnosis of the nodules that otherwise would remain suspicious. The c-KIT expression-based classification is highly accurate and may provide a tool to overcome the difficulties in today's preoperative diagnosis of thyroid suspicious malignancies.

Keywords: C-KIT, thyroid cancer, FNAC

\section{Introduction}

Thyroid carcinoma represents $90 \%$ of all endocrine malignancies and about $1 \%$ of all human malignancies, with an increasing incidence [1]. Papillary thyroid carcinoma (PTC) is its most frequent histotype and usually its first clinical presentation is a thyroid nodule [2,3]. Five to $10 \%$ of the population will develop a clinically significant

\footnotetext{
* Correspondence: c.mazzanti@med.unipi.it

+ Contributed equally

${ }^{1}$ Section of Molecular Pathology, Division of Surgical, Molecular, and Ultrastructural Pathology, University of Pisa and Pisa University Hospital, via Roma 57, Pisa, 56100, Italy

Full list of author information is available at the end of the article
}

thyroid nodule during their lifetime [4], whereas PTC accounts only for $5 \%$ of all thyroid nodules [5].

A large amount of information has been accumulated on the molecular pathogenesis of thyroid cancer [6]. For what concerns PTC, the activation of MAPK signalling pathway is a major event, as a result either of BRAF or RAS point mutations or RET/PTC rearrangement.

The proto-oncogene c-KIT is a type III receptor tyrosine-kinase, cellular homolog of the viral oncogene of the feline sarcoma retrovirus HZ4-FeSV. It plays various roles in haematopoiesis, melanogenesis and spermatogenesis, and in the development of the interstitial cells

\section{Biomed Central}


of Cajal. Its ligand is the stem cell factor (SCF) $[7,8]$. The role of c-KIT in human neoplasia is not fully cleared yet. A number of tumour types are associated with activation of c-KIT through its overexpression or through activating mutations [7,9-11], while in highly metastatic melanomas, breast cancer and thyroid carcinoma the progression into a malignant phenotype correlates mostly with loss of c-KIT expression [12-16]. Among the few papers studying c-KIT status in thyroid cancer, Natali et al. in 1995 [17] reported the loss of the receptor during the transformation of normal thyroid epithelium to papillary carcinoma. Similarly, in 2004 Mazzanti et al. [18], by using a microarray assay, were able to identify, out of thousands of genes, c-KIT as one of the most significant down-expressed gene in PTC compared to benign lesions. Other laboratories confirmed this result by using quantitative Real-Time PCR (qPCR) $[19,20]$. Moreover, multiple miRNAs, predicted to target c-KIT, have been reported to be up-regulated in PTC $[21,22]$. These findings indicate that the c-KIT receptor may be involved in the growth control of thyroid epithelium and that this function may be lost in malignant transformation.

Nowadays, thyroid fine-needle aspiration cytology (FNAC) is the best available test in the evaluation of a thyroid nodule $[23,24]$ and has greatly reduced the need for thyroid surgery. Unfortunately, a percentage of FNAC $(\sim 30 \%)$ is suspicious for papillary carcinoma (SPTC) or reveals an indeterminate follicular proliferation (IFP), not allowing a sure diagnosis of malignity or benignity [25-28]. According to the Guidelines for the Management of Thyroid Cancer, British Thyroid Association, SPCT corresponds to the abbreviation Thy 4 and IFP to Thy3.

As in other diseases, molecular pathology is playing a relevant role in diagnosis of thyroid cancer. Recently, several studies have demonstrated that the BRAF V600E mutation represents a diagnostic and prognostic biomarker in PTC, with a prevalence of $40-66 \%$, whereas it is never found in benign lesion $[29,30]$. Very recent papers of our laboratory have proposed a new simple method, named manual macrodissection, to perform molecular analysis on cells obtained by FNAC, and have demonstrated the usefulness of the association cytology-molecular biology for PTC and micro-PTC diagnosis. In particular, the analysis of the BRAF gene status increases the diagnostic accuracy for PTC of 20-30\%. However BRAF V600E analysis still leaves a percentage of SPTC and IFP, urging the finding of other molecular markers.

The present study evaluates c-KIT expression in a morpho-molecular diagnostic approach to a series of thyroid FNAC, together with the study of BRAF gene status. We confirm the down regulation of c-KIT in PTC, and show that c-KIT analysis can have a diagnostic role in thyroid FNAC.

\section{Materials and methods Specimens}

Preoperative FNAC slides of 82 thyroid nodules from as many patients were selected from files of the Section of Cytopathology, Division of Surgical, Molecular and Ultrastructural Pathology, University of Pisa, collected from 2003 to 2010. For ethical reasons, only cases with extra slides were used. Selected cells (neoplastic, SPTC or IFP) were manually scraped with a method previously described, named manual macrodissection [29].

\section{Ethical Board}

This study was approved by the Internal Review Board of the University of Pisa. All patients gave their consent for the participation to the study.

\section{Diagnosis}

Cytological diagnosis was based on the following criteria, broadly suggested in the literature: smear background, cell arrangements, cell shape, nuclear/cytoplasmic features, presence of nucleoli and mitosis. In particular, the cytological diagnosis of IFP was based on the presence of microfollicular pattern, irregularity of structure and absence of colloid, whereas nuclear atypia and mitosis were not present. Histological diagnosis assessed ultimately the malignity or benignity of all lesions.

Smears were independently reviewed by senior cytopathologists to assure adequate thyroid cell representation of the slides in which molecular analysis was performed.

The histological diagnosis of the 82 samples collected was of PTC in 46 cases and of benign nodule in 36 cases. As described in Table 1, of the 46 cases with a definitive histological diagnosis of PTC, the cytological diagnosis was of PTC in 30 cases (65\%), of SPTC in 11 cases (24\%) and of IFP in 5 cases (11\%). In the 36 cases with a definitive histological diagnosis of benign nodule, the cytological diagnosis was of benign nodule (BN) in 17 cases (47\%) and of IFP in 19 cases (53\%).

\section{DNA and RNA extraction}

Archival FNAC slides stained with Papanicolaou technique were kept in xylene for 1 to 3 days, depending on the time of storage, in order to detach the slides coverslips.

Table 1 Histological and cytological diagnoses of 82 thyroid nodules

\begin{tabular}{lccc}
\hline Histological Diagnosis & \multicolumn{3}{c}{ Cytological Diagnosis } \\
\hline & PTC & SPTC & IFP \\
\cline { 2 - 3 } PTC: 46 cases & $30(65 \%)$ & $11(24 \%)$ & $5(11 \%)$ \\
\hline & BN & IFP & \\
\cline { 2 - 3 } BN: 36 cases & $17(47 \%)$ & $19(53 \%)$ & \\
\hline
\end{tabular}

PTC: papillary thyroid carcinoma. SPTC: suspicious for PTC. IFP: indeterminate follicular proliferation. BN: benign nodule. 
Slides were then hydrated in a graded series of ethanol baths, followed by a wash in distilled $\mathrm{H}_{2} \mathrm{O}$ for 1 minute and finally air-dried. DNA extraction was performed using a commercially available kit (Nucleospin, Macherey-Nagel, Düren, Germany) with a modification to the first step. Fifty percent of the lysis solution without proteinase $\mathrm{K}$ was initially poured on the slide to scrape off the cytological stained sample using a single edged razor blade. Any scraped tissue was then collected in a microcentrifuge tube containing the other half of the lysis solution with Proteinase K. The extracted DNA was kept at $-20^{\circ}$ until used. RNA extraction was performed by using a commercial kit (High Pure RNA Paraffin kit, Roche). The quantity/quality of extracted RNA and DNA was estimated with Nanodrop 1000 spectrophotometer by using $1 \mu \mathrm{l}$ of undiluted RNA/DNA solution. RNA was then reverse transcribed in cDNA in a final volume of $20 \mu \mathrm{l}$, containing 5X RT buffer, $10 \mathrm{mM}$ dNTPs, $50 \mathrm{ng} / \mu \mathrm{l}$ Random Primers, $0.1 \mathrm{M}$ DTT, $40 \mathrm{U} / \mu \mathrm{l}$ RNaseOUT, $50 \mu \mathrm{M}$ oligo(dT), DEPCTreated Water, $15 \mathrm{U} / \mu \mathrm{l}$ Cloned AMV reverse transcriptase (Invitrogen, Carlsbad, CA).

\section{c-KIT mRNA expression analysis}

The level of c-KIT expression was analysed by quantitative Real-Time PCR (qPCR) on the Rotor-Gene 6000 real time rotary analyzer (Corbett, Life Science, Australia) following the manufacturing instructions. Endogenous reference gene (B2M, beta 2 microglobulin) was used to normalize each gene expression level. PCR was performed in $25 \mu \mathrm{l}$ final volume, containing $5 \mu \mathrm{l}$ of cDNA, $12.5 \mu \mathrm{l}$ of MESA GREEN qPCR MasterMix Plus (EUROGENTEC, San Diego, CA), $300 \mathrm{nM}$ of each primer (Invitrogen, Carlsbad, $\mathrm{CA})$ with the following cycling conditions: initial denaturation $95^{\circ} \mathrm{C}$ for $5 \mathrm{~min} ; 40$ cycles at $95^{\circ} \mathrm{C}$ for $15 \mathrm{sec}$ and $58^{\circ} \mathrm{C}$ for $40 \mathrm{sec}$ and $72^{\circ} \mathrm{C}$ for $40 \mathrm{sec}$; final step $25^{\circ} \mathrm{C}$ for $1 \mathrm{~min}$. Primers for c-KIT and B2M amplification were selected using Primer3 software:

- c-KIT F: 5' - GCACCTGCTGCTGAAATGTATGACATAAT-3'

- c-KIT R: 5' - TTTGCTAAGTTGGAGTAAATATGATTGG-3'

- B2M F: 5'- CATTCCTGAAGCTGACAGCATTC-3'

- B2M R: 5'- TGCTGGATGACGTGAGTAAACC-3'

A first PCR run was performed on control c-KIT expressing sample and run on $2 \%$ agarose gel. The PCR product was excised from the gel, purified by using GenElute ${ }^{\mathrm{TM}}$ PCR Clean-Up (Sigma-Aldrich) and measured spectrophotometrically at 260 and $280 \mathrm{~nm}$.

The purified product was diluted in a 10-fold series to create the standards for a ten-point standard curve that was run in triplicate. Standard curves were generated for both c-KIT and B2M and showed a good linearity with consistent correlation coefficient $\left(\mathrm{R}^{2}=0.999\right)$. Ct was determined by the Rotor-Gene 6000 software and exported for analysis after background subtraction. Threshold was set by standard curve and then imported in all the runs for data analysis. PCR efficiencies resulted similar for both c-KIT and B2M in each experiment and ranged between $98-102 \%$. The experiment was run in duplicate for each sample.

To verify primers specificities, melting curve analysis was performed. Fluorescent data were acquired during the extension phase. After 40 cycles a melting curve for each gene was generated by slowly increasing $\left(0.1^{\circ} \mathrm{C} / \mathrm{s}\right)$ the temperature from $60^{\circ} \mathrm{C}$ to $95^{\circ} \mathrm{C}$, while the fluorescence was measured. For each experiment a no-template reaction was included as a negative control.

c-KIT expression was ultimately represented as the ratio of absolute quantification by standard curve of c-KIT expression and B2M expression.

\section{c-KIT genotyping}

c-KIT sequence was screened for mutations in exons 9, 11, 13 and 17 by direct sequencing. PCR was performed using standard conditions: initial denaturation $95^{\circ} \mathrm{C}$ for $7 \mathrm{~min}$; 40 cycles at $95^{\circ} \mathrm{C}$ for $45 \mathrm{sec}$ and $56^{\circ} \mathrm{C}$ for $45 \mathrm{sec}$ and $72^{\circ} \mathrm{C}$ for $45 \mathrm{sec}$; final step $72^{\circ} \mathrm{C}$ for 10 min with AmpliTaq Gold (Applied Biosystems) on 9700 GeneAmp PCR System (Applied Biosystems). Primers for c-KIT sequencing were selected using Primer3 software:

- exon 9 F: 5'- CCAGGGCTTTTGTTTTCTTC-3'

- exon 9 R: 5'- TGGTAGACAGAGCCTAAACATCC-3'

- exon 11 F: 5'- GATCTATTTTTCCCTTTCTC-3'

- exon 11 R: 5' - AGCCCCTGTTTCATACTGAC-3'

- exon 13 F: 5' - TCAGTTTGCCAGTTGTGCTT-3'

- exon 13 R: 5'- AATGTCATGTTTTGATAACCT-3'

- exon 17 F: 5'- TTCTTTTCTCCTCCAACCTAA-3'

- exon 17 R: 5'- TGTCAAGCAGAGAATGGGTA-3'

The PCR products were purified with Multi Screen PCR Plates (Millipore) and the sequencing reactions were performed in $20 \mu \mathrm{l}$ final volume using Big Dye Terminator kit v3.1 (Applied Biosystems) and $2.5 \mathrm{pmol} / \mu \mathrm{l}$ of each primer, then purified with Multi Screen PCR Plates (Millipore). The sequence reactions were loaded on ABI PRISM 3100 Genetic Analyzer (Applied Biosystems) and analyzed using the Sequencing Analysis software 3.4 version.

\section{BRAF V600E mutational status}

The BRAF V600E mutational status was determined by automated pyrosequencing analysis (Qiagen).

\section{Statistical analysis}

Student's t-test was used to compare the mean of c-KIT expression between malignant and benign samples. Chisquare test was used to statistically analyse each single class of c-KIT versus the sum of the other ones. Then malignity and benignity indexes, which represent the percentage of cases with a malignant or benign diagnosis in 
each class, were calculated and the relative p-value was reported. To better estimate the significance of the malignity index trend we also performed a logistic regression. All the analyses were performed by using Statgraphics Centurion (V. 15, StatPoint, Inc.). In order to evaluate the Area Under the Curve (AUC) as a measure of sensitivity and specificity of our method, we used a ROC (receiver operating characteristic) curve analysis (Medcalc 11, Medcalc Software). To evaluate the statistical significance of the change in diagnostic accuracy before and after performing molecular analyses we used Chi-square test for comparison of two proportions (independent samples) expressed as a percentage.

\section{Results}

Expression and genotyping of c-KIT receptor in benign and malignant thyroid lesions

c-KIT expression was analyzed by qPCR in a set of 82 FNAC, histologically diagnosed as 36 benign and 46 malignant thyroid nodules (Table 2). Overall, c-KIT expression was detected in $59 \%$ of PTC $(27 / 46)$ and in $100 \%$ of BN (36/36). The mean of c-KIT expression values (c-KIT/B2M ratio) was calculated for both benign (1.72) and malignant (0.138) groups and the difference resulted highly significant $(\mathrm{p}<0.0001)$.

The sequencing of exons 9, 11, 13, 17 of the c-KIT resulted wild-type for all the samples analyzed.

\section{c-KIT expression and biological behavior of thyroid nodules}

The value of c-KIT expression (c-KIT/B2M ratio) ranged between 0 and 9.34 (Table 2). To evaluate a possible relationship with the biological behavior of lesions, c-KIT expression values (ev) were arbitrarily organized in four classes (Table 3):

- Class I: c-KIT ev =0;

- Class II: c-KIT ev > 0 and $\leq 0.5$;

- Class III: c-KIT ev > 0.5 and $\leq 3$;

- Class IV: c-KIT ev > 3;

The percentage of malignant and of benign cases was calculated in each class and its statistical significance was determined ( $\mathrm{p}$-value).

In class I the percentage of malignancy is $100 \%(19 / 19$ cases), whereas in class IV the percentage of benignity is $100 \%(5 / 5)$. In class II the percentage of malignant cases is higher than benign cases: 65\% (24/37) vs 35\% (13/37). On the other hand, class III has a higher percentage of benign cases than malignant ones: $86 \%(18 / 21)$ vs $14 \%$ (3/21). Difference between malignant and benign lesions is statistically highly significant in classes I, IV and III ( $\mathrm{p}<0.0001, \mathrm{p}=0.0091, \mathrm{p}<0.0001)$. $\mathrm{p}$-value in class II is 0.14 .

Figure 1 reports the results of fitting a logistic regression model. The p-value of the diagnostic model is less
Table 2 Morphological and molecular diagnosis in $\mathbf{8 2}$ thyroid nodules

\begin{tabular}{|c|c|c|c|c|c|}
\hline case & HD & $C D$ & c-KIT Class & c-KIT ev & BRAF \\
\hline 1 & PTC & PTC & 1 & 0 & V600E \\
\hline 2 & PTC & PTC & I & 0 & V600E \\
\hline 3 & PTC & PTC & 1 & 0 & V600E \\
\hline 4 & PTC & PTC & I & 0 & V600E \\
\hline 5 & PTC & PTC & 1 & 0 & V600E \\
\hline 6 & PTC & PTC & I & 0 & V600E \\
\hline 7 & PTC & PTC & 1 & 0 & V600E \\
\hline 8 & PTC & PTC & I & 0 & V600E \\
\hline 9 & PTC & PTC & 1 & 0 & V600E \\
\hline 10 & PTC & PTC & 1 & 0 & V600E \\
\hline 11 & PTC & PTC & 1 & 0 & V600E \\
\hline 12 & PTC & PTC & 1 & 0 & V600E \\
\hline 13 & PTC & PTC & 1 & 0 & WT \\
\hline 14 & PTC & PTC & 1 & 0 & WT \\
\hline 15 & PTC & PTC & 1 & 0 & WT \\
\hline 16 & PTC & PTC & $\|$ & 0.5 & V600E \\
\hline 17 & PTC & PTC & II & 0.448 & V600E \\
\hline 18 & PTC & PTC & $\|$ & 0.105 & V600E \\
\hline 19 & PTC & PTC & $\|$ & 0.07 & V600E \\
\hline 20 & PTC & PTC & $\|$ & 0.0533 & V600E \\
\hline 21 & PTC & PTC & $\|$ & 0.049 & V600E \\
\hline 22 & PTC & PTC & II & 0.031 & V600E \\
\hline 23 & PTC & PTC & $\|$ & 0.022 & WT \\
\hline 24 & PTC & PTC & $\|$ & 0.013 & V600E \\
\hline 25 & PTC & PTC & $\|$ & 0.0126 & WT \\
\hline 26 & PTC & PTC & $\|$ & 0.01 & WT \\
\hline 27 & PTC & PTC & $\|$ & 0.004 & WT \\
\hline 28 & PTC & PTC & ॥ & 0.0003 & WT \\
\hline 29 & PTC & PTC & $\|$ & 0.0002 & V600E \\
\hline 30 & PTC & PTC & III & 1.0506 & WT \\
\hline 31 & PTC & SPTC & 1 & 0 & WT \\
\hline 32 & PTC & SPTC & 1 & 0 & WT \\
\hline 33 & PTC & SPTC & 1 & 0 & WT \\
\hline 34 & PTC & SPTC & 1 & 0 & WT \\
\hline 35 & PTC & SPTC & $\|$ & 0.44 & V600E \\
\hline 36 & PTC & SPTC & II & 0.42 & V600E \\
\hline 37 & PTC & SPTC & $\|$ & 0.022 & V600E \\
\hline 38 & PTC & SPTC & $\|$ & 0.011 & V600E \\
\hline 39 & PTC & SPTC & $\|$ & 0.42 & WT \\
\hline 40 & PTC & SPTC & $\|$ & 0.37 & WT \\
\hline 41 & PTC & SPTC & III & 1.27 & WT \\
\hline 42 & PTC & IFP & II & 0.275 & WT \\
\hline 43 & PTC & IFP & $\|$ & 0.097 & WT \\
\hline 44 & PTC & IFP & $\|$ & 0.07 & WT \\
\hline 45 & PTC & IFP & $\|$ & 0.023 & WT \\
\hline 46 & PTC & IFP & III & 0.57 & WT \\
\hline
\end{tabular}


Table 2 Morphological and molecular diagnosis in $\mathbf{8 2}$ thyroid nodules (Continued)

\begin{tabular}{|c|c|c|c|c|c|}
\hline 47 & $\mathrm{BN}$ & $\mathrm{BN}$ & $\|$ & 0.3 & WT \\
\hline 48 & $\mathrm{BN}$ & $\mathrm{BN}$ & $\|$ & 0.14 & $W T$ \\
\hline 49 & $\mathrm{BN}$ & $\mathrm{BN}$ & $\|$ & 0.07 & WT \\
\hline 50 & $\mathrm{BN}$ & $\mathrm{BN}$ & $\|$ & 0.1079 & WT \\
\hline 51 & $\mathrm{BN}$ & $\mathrm{BN}$ & $\|$ & 0.363 & WT \\
\hline 52 & $\mathrm{BN}$ & $\mathrm{BN}$ & III & 0.561 & WT \\
\hline 53 & $\mathrm{BN}$ & $\mathrm{BN}$ & III & 0.6457 & WT \\
\hline 54 & $\mathrm{BN}$ & $\mathrm{BN}$ & III & 0.858 & WT \\
\hline 55 & $\mathrm{BN}$ & $\mathrm{BN}$ & III & 0.96 & $W T$ \\
\hline 56 & $\mathrm{BN}$ & $\mathrm{BN}$ & III & 0.97 & WT \\
\hline 57 & $\mathrm{BN}$ & $\mathrm{BN}$ & III & 1.051 & WT \\
\hline 58 & $\mathrm{BN}$ & $\mathrm{BN}$ & III & 1.3823 & WT \\
\hline 59 & $\mathrm{BN}$ & $\mathrm{BN}$ & III & 1.39 & $W T$ \\
\hline 60 & $\mathrm{BN}$ & $\mathrm{BN}$ & III & 2.47 & WT \\
\hline 61 & $\mathrm{BN}$ & $\mathrm{BN}$ & III & 2.5083 & WT \\
\hline 62 & $\mathrm{BN}$ & $\mathrm{BN}$ & III & 2.6333 & WT \\
\hline 63 & $\mathrm{BN}$ & $\mathrm{BN}$ & IV & 7.24 & WT \\
\hline 64 & $\mathrm{BN}$ & IFP & $\|$ & 0.032 & WT \\
\hline 65 & $\mathrm{BN}$ & IFP & $\|$ & 0.04 & WT \\
\hline 66 & $\mathrm{BN}$ & IFP & $\|$ & 0.0463 & WT \\
\hline 67 & $\mathrm{BN}$ & IFP & $\|$ & 0.0599 & WT \\
\hline 68 & BN & IFP & $\|$ & 0.1143 & WT \\
\hline 69 & $\mathrm{BN}$ & IFP & $\|$ & 0.1957 & WT \\
\hline 70 & $\mathrm{BN}$ & IFP & $\|$ & 0.217 & $W T$ \\
\hline 71 & $\mathrm{BN}$ & IFP & $\|$ & 0.2619 & WT \\
\hline 72 & $\mathrm{BN}$ & IFP & III & 0.7302 & WT \\
\hline 73 & $\mathrm{BN}$ & IFP & III & 0.84 & WT \\
\hline 74 & $\mathrm{BN}$ & IFP & III & 0.948 & WT \\
\hline 75 & $\mathrm{BN}$ & IFP & III & 1.09 & WT \\
\hline 76 & $\mathrm{BN}$ & IFP & III & 1.3727 & WT \\
\hline 77 & $\mathrm{BN}$ & IFP & III & 1.64 & WT \\
\hline 78 & $\mathrm{BN}$ & IFP & III & 1.67 & WT \\
\hline 79 & $\mathrm{BN}$ & IFP & IV & 3.4 & WT \\
\hline 80 & $\mathrm{BN}$ & IFP & IV & 7.69 & WT \\
\hline 81 & $\mathrm{BN}$ & IFP & IV & 8.73 & $W T$ \\
\hline 82 & BN & IFP & IV & 9.34 & WT \\
\hline
\end{tabular}

HD: histological diagnosis. CD: cytological diagnosis. C-KIT ev: C-KIT expression value. PTC: papillary thyroid carcinoma. SPTC: suspicious for PTC. BN: benign nodule. IFP: indeterminate follicular proliferation. WT: wild type.

than 0.05 , showing a statistically significant relationship between the variables at the $95 \%$ confidence level. Specificity and sensitivity of the diagnostic performance of the model were evaluated by ROC analysis and the AUC was 0.881, with C.I. 95\% 0.79-0.94 and $\mathrm{p}=0.001$, indicating that the model has a statistically significant efficacy in discriminating malignant from benign lesions (Figure 2).
Table 3 Classes of c-KIT expression value

\begin{tabular}{ccccccc}
\hline Class & \multirow{2}{*}{-KIT ev } & \multicolumn{2}{c}{ PTC } & \multicolumn{2}{c}{ BN } & p value \\
\cline { 3 - 6 } & & $\mathbf{n}$ & $\%$ & $\mathbf{n}$ & $\%$ & \\
\hline I & 0 & 19 & 100 & 0 & 0 & $<0.0001$ \\
\hline$\|$ & $>0-\leq 0.5$ & 24 & 65 & 13 & 35 & $=0.1400$ \\
\hline III & $>0.5-\leq 3.0$ & 3 & 14 & 18 & 86 & $<0.0001$ \\
\hline IV & $>3$ & 0 & 0 & 5 & 100 & $=0.0091$ \\
\hline & & 46 & & 36 & &
\end{tabular}

c-KIT ev: c-KIT expression value. PTC: papillary thyroid carcinoma. BN: benign nodule.

\section{c-KIT expression in FNAC}

The cytological diagnoses of the 46 histologically confirmed PTCs were distributed through the 4 classes as following (Table 4):

- 30 cases cytologically diagnosed as PTC: 15 (50\%) were in class I, $14(47 \%)$ in class II, $1(3 \%)$ in class III and none $(0 \%)$ in class IV.

- 11 cases cytologically diagnosed as SPTC: 4 (36\%) in class I, 6 (55\%) in class II, 1 (9\%) in class III and none $(0 \%)$ in class 4.

- 5 cases cytologically diagnosed as IFP: 4 (80\%) were in class II, $1(20 \%)$ in class III, whereas no case was present in class I and IV.

The cytological diagnoses of the 36 histologically confirmed $\mathrm{BN}$ were distributed through the 4 classes as following:

- 17 cases cytologically diagnosed as benign: 5 (29\%) were in class II, $11(65 \%)$ in class III, $1(6 \%)$ in class IV, whereas no case was present in class I.

- 19 cases cytologically diagnosed as IFP: 8 (42\%) were in class II, 7 (37\%) in class III and 4 (21\%) in class IV, whereas no case was present in class I.

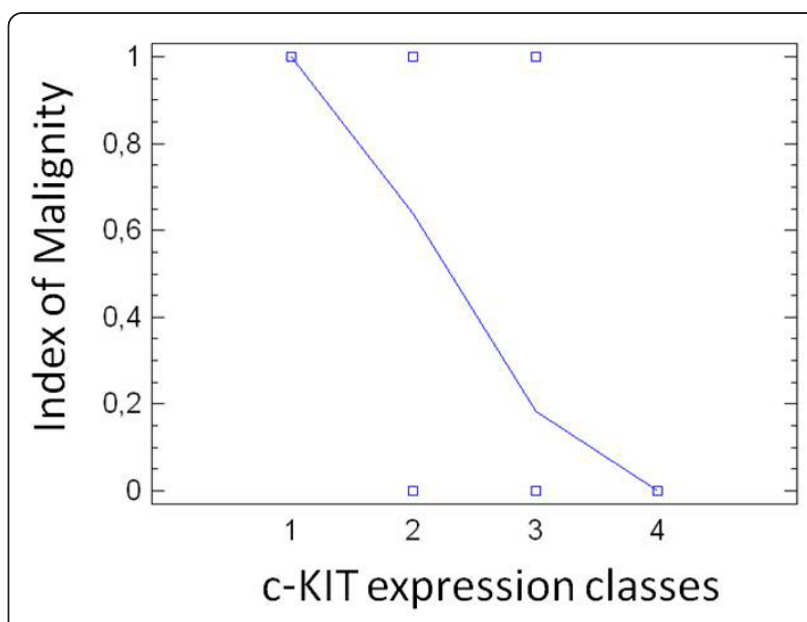

Figure 1 Logistic regression. Logistic regression model describing the relationship between the risk of malignancy and the classes of cKIT expression. The $p$-value of the model resulted to be less than 0.05 . 


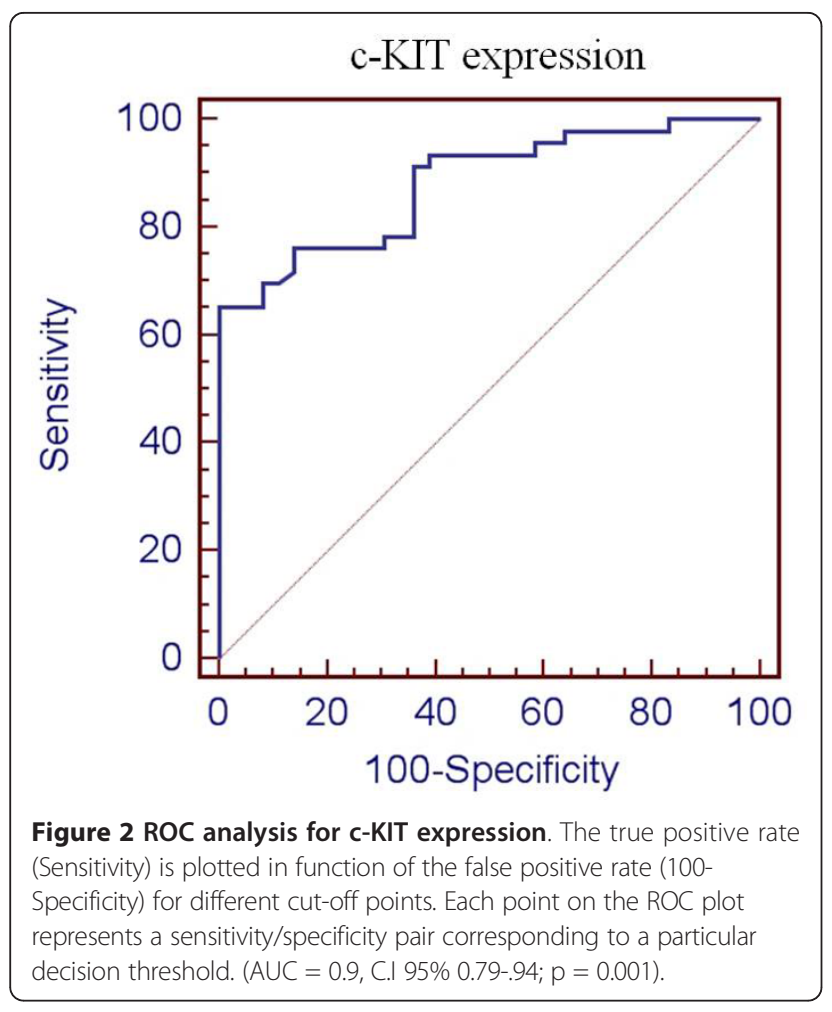

\section{BRAF V600E genotyping and c-KIT expression values of cytological samples}

The BRAF V600E mutation (Table 2) was found in 54\% of the 46 malignant samples (25/46). 48\% BRAF V600E mutated samples were in C-KIT class I (12/25), as shown in Table 5 . Class II contained the residual $52 \%$ of BRAF mutated cases (13/25). Class III and IV had no BRAF mutated cases. BRAF V600E was significantly more present in class I and II $(\mathrm{p}=0.00026)$. No benign samples were BRAF mutated.

\section{C-KIT/BRAF combined molecular analysis in thyroid nodule FNAC}

Table 5 shows that four cases of SPTC are in C-KIT class I, whereas four more cases harbor a BRAF V600E mutation. All these 8 cases can be reasonably considered as PTC. At the same time, the four cases with a cytological diagnosis of IFP that are in C-KIT class IV can reasonably considered as benign nodules.

\section{Role of molecular diagnosis in increasing the diagnostic accuracy of FNAC}

As shown in Table 6, if the 8 cases of SPTC in C-KIT class I or hosting a BRAF V600E mutation are moved to the diagnostic group of PTC, the total number of PTC rises from $30(65 \%)$ to $38(83 \%)$, with an advantage in diagnostic accuracy of malignancy of $18 \%$.

On the other hand, if the 4 cases of IFP in c-KIT class IV are moved to the diagnostic group of $\mathrm{BN}$, the total number of $\mathrm{BN}$ rises from 17 (47\%) to 21 (58\%), with an advantage in diagnostic accuracy of benignity of $11 \%$.

Finally, if we consider both PTC diagnosis and BN diagnosis, the whole diagnostic accuracy gain is of $15 \%$ with a statistically significant p-value of 0.03 .

\section{Discussion}

Papillary thyroid carcinoma (PTC) is the most common malignancy in thyroid tissue; about $80 \%$ of incident thyroid cancers are PTC. Although PTC is usually associated with alterations in the RET/PTC-RAS-BRAF signaling pathway $[31,32]$, the detailed molecular mechanism is unclear. A few papers mentioning a role for c-KIT in thyroid malignancies suggested to perform an analysis of c-KIT expression on thyroid cells obtained by FNAC from benign and malignant thyroid nodules, with the double aim to study a human model of thyroid cancer and, at the same time, to verify if c-KIT expression analysis could be of any clinical interest. The present study evaluated c-KIT expression in a group of thyroid FNAC, assessed later on as malignant or benign by post-surgical histological analysis, and describes the silencing of c-KIT in PTC. These data are in full accordance with a previous paper of Mazzanti et al. [18], who were able to identify two classifier models, of 10 and 6 genes respectively, discriminative of PTC and $\mathrm{BN}$, in

Table 4 Distribution of cytological diagnosis in the c-KIT expression classes

\begin{tabular}{|c|c|c|c|c|c|c|c|c|c|}
\hline \multirow[t]{2}{*}{ HD } & \multirow[t]{2}{*}{$C D$} & \multicolumn{2}{|c|}{ class I } & \multicolumn{2}{|c|}{ class II } & \multicolumn{2}{|c|}{ class III } & \multicolumn{2}{|c|}{ class IV } \\
\hline & & $n$ & $\%$ & $\mathrm{n}$ & $\%$ & $\mathrm{n}$ & $\%$ & $\mathrm{n}$ & $\%$ \\
\hline \multirow[t]{3}{*}{ PTC } & PTC: 30 & 15 & 50 & 14 & 47 & 1 & 3 & 0 & 0 \\
\hline & SPTC: 11 & 4 & 36 & 6 & 55 & 1 & 9 & 0 & 0 \\
\hline & IFP: 5 & 0 & 0 & 4 & 80 & 1 & 20 & 0 & 0 \\
\hline total & 46 & 19 & & 24 & & 3 & & 0 & \\
\hline \multirow[t]{2}{*}{$\mathrm{BN}$} & BN: 17 & 0 & 0 & 5 & 29 & 11 & 65 & 1 & 6 \\
\hline & IFP: 19 & 0 & 0 & 8 & 42 & 7 & 37 & 4 & 21 \\
\hline total & 36 & & & 13 & & 18 & & 5 & \\
\hline
\end{tabular}

HD: histological diagnosis. CD: cytological diagnosis. PTC: papillary thyroid carcinoma. SPTC: suspicious for PTC. IFP: indeterminate follicular proliferation. BN: benign nodule. $n$ : number of cases. 
Table 5 BRAF mutational status according to c-KIT expression classes and to morphological diagnosis

\begin{tabular}{|c|c|c|c|c|c|c|c|c|c|}
\hline \multirow[t]{2}{*}{ HD } & \multirow[t]{2}{*}{$C D$} & \multicolumn{2}{|c|}{ class I } & \multicolumn{2}{|c|}{ class II } & \multicolumn{2}{|c|}{ class III } & \multicolumn{2}{|c|}{ class IV } \\
\hline & & V600E & WT & V600E & WT & V600E & WT & V600E & WT \\
\hline \multirow[t]{3}{*}{ PTC: 46} & PTC: 30 & 12 & 3 & 9 & 5 & 0 & 1 & 0 & 0 \\
\hline & SPTC: 11 & 0 & 4 & 4 & 2 & 0 & 1 & 0 & 0 \\
\hline & IFP: 5 & 0 & 0 & 0 & 4 & 0 & 1 & 0 & 0 \\
\hline \multirow[t]{2}{*}{ BN: 36} & BN: 17 & 0 & 0 & 0 & 5 & 0 & 11 & 0 & 1 \\
\hline & IFP: 19 & 0 & 0 & 0 & 8 & 0 & 7 & 0 & 4 \\
\hline
\end{tabular}

HD: histological diagnosis. CD: cytological diagnosis. WT: wild type. PTC: papillary thyroid carcinoma. SPTC: suspicious for PTC. IFP: indeterminate follicular proliferation.

both of which c-KIT gene was included. In this analysis c-KIT resulted heterogeneously expressed in goiters, whereas PTC were negative. These data give also strength to the report that multiple miRNAs predicted to target c-KIT (miR-221, miR-222, miR-146) are upregulated in PTC [21,22].

The biological significance of loss of c-KIT in thyroid malignancies is not clear. SCF, the c-KIT ligand, is not mitogenic in primary cultures of thyrocytes even in conjunction with thyroid-stimulating hormone [33], a result which would indicate that SCF/C-KIT pathway may control some aspects of the thyrocyte differentiated phenotype rather than cell division. This would agree with the apparently strong selection for loss of c-KIT expression in neoplastic transformation of thyroid epithelium. This negative selection is in stark contrast with the gain of function due to genetic alterations of tyrosine kinase receptors (TRKs) in other types of cancers, suggesting that TRK signaling pathways may have opposite biological effects in different cell types.

To explore the diagnostic utility of c-KIT expression in thyroid nodules, its expression values were divided in four arbitrarily defined classes, with class I characterized by the complete silencing of the gene. Class I and IV represented the two most informative groups, with $100 \%$ of the samples found malignant or benign respectively. Class III was also very informative including $86 \%$ of benign samples and having over all the highest statistical significance. On the other hand, in class II the samples

Table 6 Role of molecular diagnosis in increasing the diagnostic accuracy of FNAC

\begin{tabular}{cccc}
\hline CD & c-KIT class I & BRAF V600E & c-KIT class IV \\
\hline SPTC & 4 & 4 & \\
\hline IFP & & & 4 \\
\hline & CD & MD & DA \\
\hline PTC & $30 / 46: 65 \%$ & $38 / 46: 83 \%$ & $+18 \%$ \\
\hline BN & $17 / 36: 47 \%$ & $21 / 36: 58 \%$ & $+11 \%$ \\
\hline PTC + BN & $47 / 82: 57 \%$ & $59 / 82: 72 \%$ & $+15 \%$
\end{tabular}

CD: cytological diagnosis. PTC: papillary thyroid carcinoma. SPTC: suspicious for PTC. BN: benign nodule. MD: molecular diagnosis. DA: diagnostic accuracy. belonging to the malignant group were $66 \%$, which resulted non significant. A ROC analysis was performed to measure the diagnostic performance of the model (Figure 2), showing its good efficacy in predicting the malignant events (AUC $=0.9$ C.I 95\% 0.79-.94; $\mathrm{p}=$ $0.001)$. However, we did not test C-KIT model on unknown samples, since cytological smears employed in this study were obtained from nodules whose histological diagnosis was known. Thus, additional blind samples are required to strengthen the utility of c-KIT test in the preoperative diagnosis.

Moreover, quite interestingly, BRAF V600E mutation, which is a well-known marker for PTC, was found to be statistically more present in the c-KIT classes I and II, while class III and IV did not contain any sample, supporting therefore the association of low c-KIT expression levels to a malignant status.

Molecular Pathology is the modern version of Pathology, where the whole of morphology and molecular alterations represents a powerful approach to diagnosis. In this line, this study aimed to verify the diagnostic potential of c-KIT expression analysis and demonstrated that the combined BRAF mutation and c-KIT expression approach is able to increase the diagnostic accuracy of FNAC of thyroid nodules of $18 \%$ for a diagnosis of malignancy and $11 \%$ for a diagnosis of benignity.

Despite several carcinomas showed activating mutations of c-KIT gene (GISTs, melanomas, haematopoietic and lymphoid tumors), they have not been described in thyroid tumors and this study revealed a wild type sequence of c-KIT gene in exons 9, 11, 13, and 17.

Finally, as previously published by Jin et al. [34], the present paper shows that not only DNA but RNA too can be easily extracted from stained smears of FNAC and easily analyzed by qPCR. c-KIT receptor expression was detectable regardless of the time of specimen collection from the archived material, we were able to successfully use slides prepared 7 years ago and kept in our archives. Moreover all of the smears were independently reviewed by a senior cytopathologist before assessing c-KIT expression, to assure adequate thyroid cell representation of the slides in which c-KIT receptor expression was 
investigated. The simple method named manual macrodissection and described elsewhere allows to perform molecular analysis only on selected cell population to be studied. This specialized test that may have increased utility as testing based on RNA is becoming more widespread and easily available.

\section{Conclusion}

In summary, we have demonstrated that c-KIT expression-based classification of thyroid lesions is highly accurate and may provide a tool to overcome the difficulties in today's preoperative diagnosis of thyroid suspicious malignancies. We hoped that the test proposed in this paper will be a useful adjunct to the preoperative diagnosis of thyroid nodules.

\section{Author details \\ ${ }^{1}$ Section of Molecular Pathology, Division of Surgical, Molecular, and Ultrastructural Pathology, University of Pisa and Pisa University Hospital, via Roma 57, Pisa, 56100, Italy. ${ }^{2}$ Section of Cytopathology, Division of Surgical, Molecular, and Ultrastructural Pathology, University of Pisa and Pisa University Hospital, via Roma 57, Pisa, 56100, Italy. ${ }^{3}$ Department of Human Morphology and Applied Biology, University of Pisa and Pisa University Hospital, via Volta 4, Pisa, 56100, Italy.}

\section{Authors' contributions}

ST carried out the study, analyzed the data and wrote the manuscript draft. CM and GB conceived of the manuscript, participated in its design, coordination, analysis and interpretation of data and supervised the writing of the manuscript. PA participated in the statistical data analysis. All the authors made intellectual contributions and approved the final manuscript.

\section{Competing interests}

The authors declare that they have no competing interests.

Received: 12 October 2011 Accepted: 10 January 2012 Published: 10 January 2012

\section{References}

1. Hodgson NC, Button J, Solorzano CC: Thyroid cancer: is the incidence still increasing? Ann Surg Oncol 2004, 11:1093-1097.

2. Miccoli P, Minuto MN, Galleri D, D'Agostino J, Basolo F, Antonangeli L, Aghini-Lombardi F, Berti P: Incidental thyroid carcinoma in a large series of consecutive patients operated on for benign thyroid disease. ANZ J Surg 2006, 76:123-126.

3. Udelsman $\mathrm{R}$, Chen $\mathrm{H}$ : The current management of thyroid cancer. Adv Surg 1999, 33:1-27.

4. Mazzaferri EL: Management of a solitary thyroid nodule. N Engl J Med 1993, 328:553-559

5. Hegedus L: Clinical practice. The thyroid nodule. N Engl J Med 2004, 351:1764-1771

6. Nikiforov YE: Thyroid carcinoma: molecular pathways and therapeutic targets. Mod Pathol 2008, 21(Suppl 2):S37-43.

7. de Silva CM, Reid R: Gastrointestinal stromal tumors (GIST): C-kit mutations, CD117 expression, differential diagnosis and targeted cancer therapy with Imatinib. Pathol Oncol Res 2003, 9:13-19.

8. Ronnstrand L: Signal transduction via the stem cell factor receptor/c-Kit. Cell Mol Life Sci 2004, 61:2535-2548.

9. D'Amato G, Steinert DM, MCAuliffe JC, Trent JC: Update on the biology and therapy of gastrointestinal stromal tumors. Cancer Control 2005, 12:44-56.

10. Miettinen M, Makhlouf $H$, Sobin $L H$, Lasota J: Gastrointestinal stromal tumors of the jejunum and ileum: a clinicopathologic, immunohistochemical, and molecular genetic study of 906 cases before imatinib with long-term follow-up. Am J Surg Pathol 2006, 30:477-489.
11. McIntyre A, Summersgill B, Grygalewicz B, Gillis AJ, Stoop J, van Gurp RJ, Dennis N, Fisher C, Huddart R, Cooper C, Clark J, Oosterhuis JW, Looijenga LH, Shipley J: Amplification and overexpression of the KIT gene is associated with progression in the seminoma subtype of testicular germ cell tumors of adolescents and adults. Cancer Res 2005, 65:8085-8089.

12. All-Ericsson C, Girnita L, Muller-Brunotte A, Brodin B, Seregard S, Ostman A Larsson O: c-Kit-dependent growth of uveal melanoma cells: a potential therapeutic target? Invest Ophthalmol Vis Sci 2004, 45:2075-2082.

13. Huang S, Luca M, Gutman M, McConkey DJ, Langley KE, Lyman SD, BarEli M: Enforced c-KIT expression renders highly metastatic human melanoma cells susceptible to stem cell factor-induced apoptosis and inhibits their tumorigenic and metastatic potential. Oncogene 1996, 13:2339-2347.

14. Ko CD, Kim JS, Ko BG, Son BH, Kang HJ, Yoon HS, Cho EY, Gong G, Ahn SH: The meaning of the c-kit proto-oncogene product in malignant transformation in human mammary epithelium. Clin Exp Metastasis 2003, 20:593-597.

15. Tsutsui S, Yasuda K, Suzuki K, Takeuchi H, Nishizaki T, Higashi H, Era S: A loss of c-kit expression is associated with an advanced stage and poor prognosis in breast cancer. Br J Cancer 2006, 94:1874-1878.

16. Ulivi P, Zoli W, Medri L, Amadori D, Saragoni L, Barbanti F, Calistri D, Silvestrini R: c-kit and SCF expression in normal and tumor breast tissue. Breast Cancer Res Treat 2004, 83:33-42.

17. Natali PG, Berlingieri MT, Nicotra MR, Fusco A, Santoro E, Bigotti A, Vecchio G: Transformation of thyroid epithelium is associated with loss of c-kit receptor. Cancer Res 1995, 55:1787-1791.

18. Mazzanti C, Zeiger MA, Costouros NG, Umbricht C, Westra WH, Smith D, Somervell H, Bevilacqua G, Alexander HR, Libutti SK: Using gene expression profiling to differentiate benign versus malignant thyroid tumors. Cancer Res 2004, 64:2898-2903.

19. Prasad NB, Somervell H, Tufano RP, Dackiw AP, Marohn MR, Califano JA, Wang Y, Westra WH, Clark DP, Umbricht CB, Libutti SK, Zeiger MA: Identification of genes differentially expressed in benign versus malignant thyroid tumors. Clin Cancer Res 2008, 14:3327-3337.

20. Rosen J, He M, Umbricht C, Alexander HR, Dackiw AP, Zeiger MA, Libutti SK. A six-gene model for differentiating benign from malignant thyroid tumors on the basis of gene expression. Surgery 2005, 138:1050-1056, discussion 1056-1057.

21. He H, Jazdzewski K, Li W, Liyanarachchi S, Nagy R, Volinia S, Calin GA, Liu CG, Franssila K, Suster S, Kloos RT, Croce CM, de la Chapelle A: The role of microRNA genes in papillary thyroid carcinoma. Proc Natl Acad Sci USA 2005, 102:19075-19080

22. Mazeh H, Mizrahi I, Halle D, llyayev N, Stojadinovic A, Trink B, MitraniRosenbaum S, Roistacher M, Ariel I, Eid A, Freund HR, Nissan A: Development of a microRNA-based molecular assay for the detection of papillary thyroid carcinoma in aspiration biopsy samples. Thyroid 2011, 21:111-118.

23. Hamberger B, Gharib H, Melton L, Goellner JR, Zinsmeister AR: Fine-needle aspiration biopsy of thyroid nodules. Impact on thyroid practice and cost of care. Am J Med 1982, 73:381-384.

24. Suen KC: How does one separate cellular follicular lesions of the thyroid by fine-needle aspiration biopsy? Diagn Cytopathol 1988, 4:78-81.

25. Caraway NP, Sneige N, Samaan NA: Diagnostic pitfalls in thyroid fineneedle aspiration: a review of 394 cases. Diagn Cytopathol 1993, 9:345-350.

26. Goellner JR: Problems and pitfalls in thyroid cytology. Monogr Pathol 1997, 75-93.

27. Goellner JR, Gharib H, Grant CS, Johnson DA: Fine needle aspiration cytology of the thyroid, 1980 to 1986. Acta Cytol 1987, 31:587-590.

28. Ravetto C, Colombo L, Dottorini ME: Usefulness of fine-needle aspiration in the diagnosis of thyroid carcinoma: a retrospective study in 37,895 patients. Cancer 2000, 90:357-363.

29. Marchetti I, Lessi F, Mazzanti CM, Bertacca G, Elisei R, Coscio GD, Pinchera A, Bevilacqua G: A morpho-molecular diagnosis of papillary thyroid carcinoma: BRAF V600E detection as an important tool in preoperative evaluation of fine-needle aspirates. Thyroid 2009, 19:837-842.

30. Xing M: BRAF mutation in papillary thyroid cancer: pathogenic role, molecular bases, and clinical implications. Endocr Rev 2007, 28:742-762.

31. Kimura ET, Nikiforova MN, Zhu Z, Knauf JA, Nikiforov YE, Fagin JA: High prevalence of BRAF mutations in thyroid cancer: genetic evidence for 
constitutive activation of the RET/PTC-RAS-BRAF signaling pathway in papillary thyroid carcinoma. Cancer Res 2003, 63:1454-1457.

32. Melillo RM, Castellone MD, Guarino V, De Falco V, Cirafici AM, Salvatore G, Caiazzo F, Basolo F, Giannini R, Kruhoffer M, Orntoft T, Fusco A, Santoro M: The RET/PTC-RAS-BRAF linear signaling cascade mediates the motile and mitogenic phenotype of thyroid cancer cells. J Clin Invest 2005, 115:1068-1081.

33. Zsebo KM, Williams DA, Geissler EN, Broudy VC, Martin FH, Atkins HL, Hsu RY, Birkett NC, Okino KH, Murdock DC, et al: Stem cell factor is encoded at the $\mathrm{Sl}$ locus of the mouse and is the ligand for the c-kit tyrosine kinase receptor. Cell 1990, 63:213-224.

34. Jin L, Lloyd RV, Nassar A, Lappinga PJ, Sebo TJ, Swartz K, Seys AR, EricksonJohnson MR, Roth CW, Evers BR, Oliveira AM, Zhang J: HMGA2 expression analysis in cytological and paraffin-embedded tissue specimens of thyroid tumors by relative quantitative RT-PCR. Diagn Mol Pathol 2011, 20:71-80.

doi:10.1186/1479-5876-10-7

Cite this article as: Tomei et al: c-KIT receptor expression is strictly associated with the biological behaviour of thyroid nodules. Journal of Translational Medicine 2012 10:7.

\section{Submit your next manuscript to BioMed Central} and take full advantage of:

- Convenient online submission

- Thorough peer review

- No space constraints or color figure charges

- Immediate publication on acceptance

- Inclusion in PubMed, CAS, Scopus and Google Scholar

- Research which is freely available for redistribution

Submit your manuscript at www.biomedcentral.com/submit
Ciomed Central 